\title{
REVIEW
}

\section{Methemoglobinemia in the Operating Room and Intensive Care Unit: Early Recognition, Pathophysiology, and Management}

\author{
John N. Cefalu • Tejas V. Joshi · Matthew J. Spalitta · Carson J. Kadi • \\ James H. Diaz · Jonathan P. Eskander · Elyse M. Cornett •
}

Alan D. Kaye

Received: March 28, 2019 / Published online: March 19, 2020

(c) The Author(s) 2020

\section{ABSTRACT}

The objectives of this review are to describe the acquired and hereditary causes of methemoglobinemia, to recommend the most sensitive diagnostic tests, and to enable critical care clinicians to rapidly detect and treat methemoglobinemia. To meet these objectives, Internet search engines were queried with the

Enhanced Digital Features To view enhanced digital features for this article go to https://doi.org/10.6084/ m9.figshare.11907084.

J. N. Cefalu · T. V. Joshi · M. J. Spalitta .

C. J. Kadi · J. H. Diaz · A. D. Kaye ( $\triangle)$

Department of Anesthesiology, Louisiana State

University Health Sciences Center, Room 656, 1542

Tulane Avenue, New Orleans, LA 70112, USA

e-mail: alankaye44@hotmail.com

J. H. Diaz

Department of Public Health, Louisiana State

University Health Sciences Center, 1542 Tulane

Avenue, New Orleans, LA 70112, USA

\section{J. P. Eskander}

Department of Anesthesiology, Portsmouth

Anesthesia Associates, 3200 Tyre Neck Rd Suite 101,

Portsmouth, VA 23703, USA

\section{E. M. Cornett}

Department of Anesthesiology, Louisiana State

University Health Sciences Center Shreveport, 1501

Kings Highway, Shreveport, LA 71103, USA keywords to select articles for review that included case reports, case series, observational, longitudinal, and surveillance studies. The most common causes of methemoglobinemia include oxidizing reactions to cocaine-derived anesthetics, such as benzocaine and lidocaine, to antibiotics, such as dapsone and other sulfonamides, and to gases, such as nitric oxide. Additionally, CO-oximetry is superior to standard pulse oximetry in detecting methemoglobinemia. Finally, effective treatments for methemoglobinemia include intravenous administration of methylene blue, ascorbic acid, and riboflavin. In this manuscript we will discuss methemoglobinemia, how it occurs, and how to treat it.

Keywords: Ascorbic acid; Benzocaine; Dapsone; Hyperbaric oxygen; Lidocaine; Methemoglobinemia; Methylene blue; Nitric oxide; Pain; Riboflavin 


\section{Key Summary Points}

Methemoglobinemia can present as a challenge for clinicians to both diagnose and treat in the intensive care unit and the operating room.

Clinically, methemoglobinemia may manifest as dyspnea, nausea, cyanosis, and tachycardia to much more extreme symptoms such as lethargy, stupor, and deteriorating consciousness.

Methemoglobinemia can be diagnosed by a discrepancy between the $\mathrm{SpO} 2$ and $\mathrm{SaO} 2$ that is refractory to oxygen therapy, signs of cyanosis, decreased $\mathrm{SpO} 2$ hovering at $85 \%$, chocolate-colored blood, acidosis and tachycardia, and most effectively with use of CO-oximetry.

The most common drugs that cause methemoglobinemia include cocainederived anesthetics such as benzocaine and lidocaine, antibiotics such as dapsone, and gases such as nitric oxide.

A variety of inherited forms of methemoglobinemia exist including congenital methemoglobinemia, hemoglobin $\mathrm{M}$ disease, glucose-6phosphate dehydrogenase (G6PD) deficiency, and autosomal recessive deficiency of cytochrome b5 reductase in which oxidant drugs should be avoided and exchange transfusion may be beneficial.

Treatments of methemoglobinemia include methylene blue, ascorbic acid, riboflavin, hyperbaric oxygen therapy, and even RBC transfusion for refractory or severe cases. Methylene blue is used for cases primarily caused secondary to drug exposure.

\section{INTRODUCTION}

There are many causes of hypoxia in the perioperative period and in the intensive care unit (ICU) ranging from airway obstruction to hemoglobinopathies. Surrogate measurements such as transcutaneous oxygen saturation by pulse oximetry are often used for the rapid assessment of patient oxygenation status. Any delays in the correction of acute hypoxia can have significant consequences including cardiac arrest and brain damage. Therefore, clinicians must be able to recognize, respond to, and treat both common and uncommon causes of oxygen desaturation and hypoxia.

Methemoglobinemia is an uncommon, often overlooked, and potentially reversible cause of hypoxia in the perioperative setting. Methemoglobinemia occurs when the bound ferrous iron $\left(\mathrm{Fe}^{2+}\right)$ of oxyhemoglobin is oxidized to the bound ferric iron $\left(\mathrm{Fe}^{3+}\right)$ of methemoglobin. An indication of methemoglobinemia is a discrepancy between the transcutaneous oxygen saturation (SpO2) and the calculated arterial oxygen saturation on arterial blood gas (SaO2). Furthermore, a decreased $\mathrm{SpO} 2$ often with a nadir of $85 \%$, chocolate-colored or black/brown blood, physiologically appropriate partial pressure of oxygen ( $\mathrm{PaO} 2)$ on arterial blood gas $(\mathrm{ABG})$, metabolic acidosis, and tachycardia are all associated with methemoglobinemia.

The symptoms of methemoglobinemia relate to the level of methemoglobin in the blood [1]. Dyspnea, nausea, and tachycardia occur at methemoglobin levels generally greater than $30 \%$, while lethargy, stupor, and deteriorating consciousness occur as methemoglobin levels reach 50\% [2]. It should be noted that in patients with lifelong congenital methemoglobinemia or with a history of chronic methemoglobinemia secondary to chronic exposure to drugs or toxins, methemoglobin levels can be as high as $40 \%$ [3] and still be well tolerated with cyanosis (blueish cast to the mucous membranes of the skin) being the only presenting manifestation.

Genetic risk factors for methemoglobinemia include hemoglobin $\mathrm{M}$ disease, glucose-6-phosphate dehydrogenase (G6PD) deficiency, and 
congenital methemoglobinemia genotypes. Only early recognition of high-risk factors for methemoglobinemia will prevent perioperative hypoxia in the operating room and ICU. A discrepancy between $\mathrm{SpO} 2$ and the calculated $\mathrm{SaO} 2$ may be the earliest indicator of methemoglobinemia.

Factors that increase a patient's risk for developing methemoglobinemia include having pre-existing conditions such as cardiovascular or pulmonary diseases and/or anemia. These patients should be treated regardless of symptoms when methemoglobin levels reach $10 \%$. All patients with methemoglobin levels of $30 \%$ or more should be treated with an appropriate therapy regardless of symptoms. Those at the extremes of age are also at increased risk for developing methemoglobinemia in the perioperative setting.

The most common drugs that cause methemoglobinemia include cocaine-derived anesthetics such as benzocaine and lidocaine, antibiotics such as dapsone, and gases such as nitric oxide. Positive clinical data does exist regarding the benefits of co-administration of cimetidine in patients requiring long-term dapsone therapy. Hemoglobin M, a genetic disease which will be discussed in more detail, does not respond to ascorbic acid or methylene blue treatment. In this situation, exchange transfusion may be beneficial. Dextrose should be given in addition to methylene blue as it is used to form nicotinamide adenine dinucleotide phosphate (NADPH) through the hexose monophosphate shunt.

Treatments for methemoglobinemia will be discussed in more detail but include red blood cell exchange transfusions and hyperbaric oxygen therapy, which may be indicated in refractory cases.

The objectives of this review are (1) to describe the acquired and hereditary causes of methemoglobinemia, (2) to recommend the most sensitive diagnostic laboratory tests, and (3) to enable critical care clinicians to rapidly detect methemoglobinemia in unconscious patients and administer appropriate rescue therapies.

\section{METHODS}

To conduct this review, several Internet search engines, including Google, Google Scholar, PubMed, Ovid, and Cochrane, were queried with the keywords. The searched keywords included methemoglobinemia, benzocaine, lidocaine, dapsone, nitric oxide, methylene blue, ascorbic acid, riboflavin, and hyperbaric oxygen therapy. The scientific articles selected for review included review articles, case reports, case series, and observational and longitudinal studies. Articles excluded from review included diagnostic laboratory reports, pathophysiological reports, and clinical pathological case conference presentations. The study period was defined as 1990 to the present. This article is based on previously conducted studies and does not contain any studies with human participants or animals performed by any of the authors.

\section{RESULTS}

\section{Pathophysiology of Methemoglobinemia}

Methemoglobinemia is characterized by elevated blood levels of hemoglobin $(\mathrm{Hb})$ containing oxidized ferric $(+3)$ iron $(\mathrm{Fe})$ rather than ferrous $(+2) \mathrm{Fe}$ [4]. Hb with ferric Fe cannot reversibly bind oxygen $\left(\mathrm{O}_{2}\right)$ and has increased affinity for the $\mathrm{O}_{2}$ bound to the other functional ferrous heme groups, further preventing delivery of $\mathrm{O}_{2}$ to tissue $[5,6]$. Because methemoglobin cannot effectively deliver $\mathrm{O}_{2}$ to peripheral tissue and organs, the oxyhemoglobin dissociation curve is shifted left and hypoxia results [7]. The pathogenesis of methemoglobinemia is either congenital or acquired and consists of four main types: severe, acute acquired, chronic mild, and chronic. Severe is life threatening and requires immediate emergency therapy. Acute acquired requires the cessation of the inducing agent and immediate emergency therapy. Chronic mild may present as asymptomatic with cyanosis (or no cyanosis), and there is no specific therapy required. Finally, chronic methemoglobinemia requires medications to reduce cyanosis such as 


\begin{tabular}{ll}
$\begin{array}{l}\text { Types of } \\
\text { methemoglobinemia }\end{array}$ & Treatment \\
\hline $\begin{array}{l}\text { Severe } \\
\text { methemoglobinemia }\end{array}$ & $\begin{array}{l}\text { Need emergency therapy (It is } \\
\text { life-threatening) }\end{array}$ \\
$\begin{array}{l}\text { Acute acquired } \\
\text { methemoglobinemia }\end{array}$ & $\begin{array}{l}\text { Need to stop administration of inducing } \\
\text { agent and emergency therapy }\end{array}$ \\
$\begin{array}{l}\text { Chronic mild } \\
\text { methemoglobinemia }\end{array}$ & $\begin{array}{l}\text { Can be fully asymptomatic with cyanosis } \\
\text { or not and no specific therapy required. }\end{array}$ \\
$\begin{array}{l}\text { Chronic } \\
\text { methemoglobinemia }\end{array}$ & Medications to reduce cyanosis Methylene \\
\hline
\end{tabular}

Fig. 1 Types of methemoglobinemia. Reproduced from [1]

methylene blue, citric acid, or oxygen. These will be discussed in more detail below. See Fig. 1, used with permission from [1].

\section{Risk Factors for Methemoglobinemia}

Various pre-existing medical conditions can also predispose a person to developing methemoglobinemia during and outside of the perioperative setting. Under normal physiologic conditions in healthy individuals, approximately $1 \%$ of total hemoglobin exists as oxidized methemoglobin [8]. In congenital methemoglobinemia, the enzyme responsible for the reduction of ferric methemoglobin to ferrous oxyhemoglobin, cytochrome b5 reductase, is deficient which results in decreased reduction of methemoglobin back to oxyhemoglobin. This deficiency can be present in all cells, as seen in type II congenital methemoglobinemia or absent only in red blood cells (RBCs) as seen in type I congenital methemoglobinemia [9].

Hemoglobin $\mathrm{M}$ disease is an autosomal dominant genetic disorder resulting from mutation in either the alpha, beta, or gamma chains of the hemoglobin molecule. These mutations result in hemoglobin that resists reduction from the oxidized ferric state back to the ferrous state. This causes a permanent increase in levels of methemoglobin ranging between $15 \%$ and $30 \%$.

Heterozygotes of the autosomal recessive deficiency in cytochrome b5 reductase are at an increased risk of developing clinically significant methemoglobinemia in the perioperative setting when compared to homozygotes. This may result from the lack of compensation present in the heterozygotes, which is otherwise present in the homozygotes from the chronicity of phenotype [10]. Even in light of the varying degrees of compensation seen in patients with congenital methemoglobinemia, conditions causing imbalances in the supply/demand ratio of $\mathrm{O}_{2}$ can lead to decompensation and development of severe symptoms of hypoxia [11].

Pre-existing conditions including cardiovascular disease and/or anemia place all patients at an increase susceptibility to develop acute symptoms of hypoxia in the setting of exposure to various oxidizing agents in the environment and perioperative setting [12]. Thus, it is recommended for patients intolerant to reduction in oxygen carrying capacity, including those with coronary artery disease, peripheral vascular disease, cerebrovascular disease, sepsis, respiratory disease, acidosis and/or anemia, that they be treated regardless of symptoms when methemoglobin levels reach 10\%. Furthermore, it is recommended that all patients with methemoglobin levels of $30 \%$ or more be treated with an appropriate therapy regardless of symptoms [11].

Infants and premature infants have only half the erythrocyte cytochrome b5 reductase activity seen in adults. As such, they are more susceptible to the development of methemoglobinemia [13]. The elderly are also at an increased risk of developing methemoglobinemia [8]. Patients with G6PD deficiency are at an increased risk of developing methemoglobinemia because the deficit in the G6PD enzyme causes red blood cells to prematurely break down. G6PD is the most prevalent enzyme deficiency, occurring almost exclusively in male individuals, with an estimated 400 million people affected worldwide [14]. Overall, however, the majority of cases of methemoglobinemia are due to exposure to medications and others toxic agents [4, 11]. Common agents implicated in causing methemoglobinemia are listed in Table 1 [15].

\section{Diagnosis of Methemoglobinemia}

Methemoglobinemia can be assessed in the intraoperative setting through several methods. 
Table 1 Agents that may cause methemoglobinemia. Modified from [15]

\begin{tabular}{|c|c|}
\hline Classes & Drugs \\
\hline Acetamides & Phenacetin \\
\hline Analgesics & Phenazopyridine \\
\hline Antibiotics & $\begin{array}{l}\text { Dapsone, } \\
\text { trimethoprim, sulfonamides }\end{array}$ \\
\hline Antigout agents & Rasburicase \\
\hline Antimalarials & Chloroquine, primaquine \\
\hline Antineoplastic agents & Cyclophosphamide, flutamide \\
\hline $\begin{array}{l}\text { Industrial/household } \\
\text { products }\end{array}$ & $\begin{array}{l}\text { Aniline dyes, naphthalene, } \\
\text { aminophenols, chlorates, } \\
\text { bromates, herbicides, and } \\
\text { pesticides }\end{array}$ \\
\hline Local anesthetics & $\begin{array}{l}\text { Articaine, benzocaine, lidocaine, } \\
\text { prilocaine }\end{array}$ \\
\hline Nitrate derivatives & Nitrates salt, nitroglycerin \\
\hline Nitrite derivatives & $\begin{array}{l}\text { Nitroprusside, amyl nitrite, nitric } \\
\text { oxide }\end{array}$ \\
\hline Prokinetic agents & Metoclopramide \\
\hline
\end{tabular}

See Fig. 2, reused with permission [1]. One of the first and most readily available clues that methemoglobinemia is present is cyanosis, or a blueish hue to the mucous membranes of the hands and feet and is easily detected by the naked eye. Furthermore, sulfhemoglobinemia, a rare but potentially comorbid condition to methemoglobinemia, may also occur and present as cyanosis. Sulfhemoglobinemia is caused by excess sulfhemoglobin in the blood, which is the product of the irreversible binding of sulfur by the hemoglobin in red blood cells which makes them unable to transport oxygen. It can result from ingestion of dapsone, phenacetin, and sulfonamides; therefore, the health care provider must consider this as a differential diagnosis [10]. The most clinically effective method of methemoglobin detection is through use of a CO-oximeter, which directly measures the light wavelength absorption of

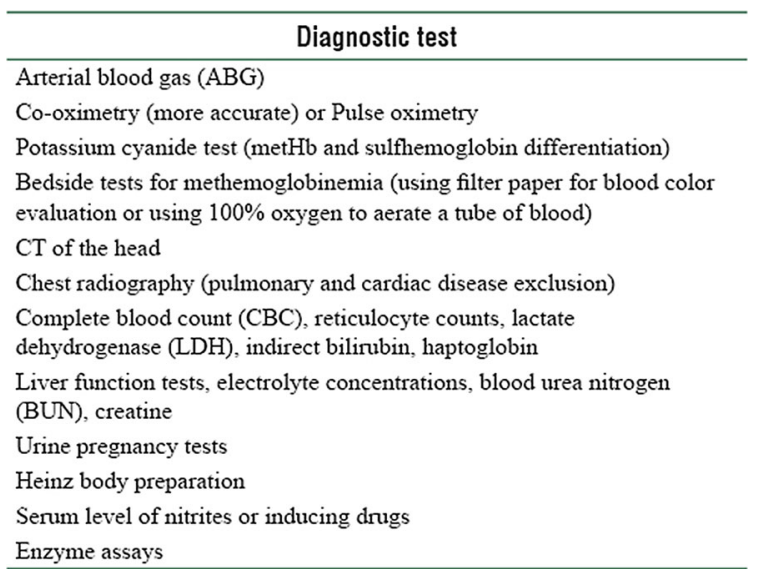

Fig. 2 Diagnosis of methemoglobinemia. Reproduced from [1]

methemoglobin in the blood. In standard pulse oximetry, light absorption is measured at wavelengths of $660 \mathrm{~nm}$ and $940 \mathrm{~nm}$, allowing calculation of the oxyhemoglobin to deoxyhemoglobin ratio. The pulse oximeter then translates this ratio into an estimated percentage of blood oxygen saturation, with an oxyhemoglobin to deoxyhemoglobin ratio of 1 corresponding to an oxygen saturation of approximately $85 \%$ [16]. This is of clinical importance since methemoglobin absorbs light equally at wavelengths of $660 \mathrm{~nm}$ and $940 \mathrm{~nm}$ [16]. Thus, as methemoglobin levels in the blood increase, oxygen saturation would be expected to hover around $85 \%$ due to the equal absorbance occurring at the $660 \mathrm{~nm}$ and $940 \mathrm{~nm}$ wavelengths.

The advantage of CO-oximetry in evaluating methemoglobinemia is that it measures light absorbance at two additional wavelengths, $600 \mathrm{~nm}$ and $631 \mathrm{~nm}$, compared to standard pulse oximetry [16]. Multiple wavelength COoximetry, thus, provides physicians with a noninvasive method for intraoperatively assessing methemoglobin, which also absorbs light at a $631 \mathrm{~nm}$ wavelength. The specificity of COoximetry for detecting methemoglobin can be further improved by addition of the EvelynMalloy assay, also known as the acid diazo coupling method, which is the most widely used industrial reaction in the production of dyes, helps to eliminate methylene blue and sulfhemoglobin as possible false positives [12]. 
The assay provides cyanide binding of methemoglobin and subsequent alteration of the $631 \mathrm{~nm}$ absorption peak.

Hypoxia and cyanosis in the setting of discrepancy between the $\mathrm{SpO} 2$ and the $\mathrm{SaO} 2$ that is refractory to oxygen therapy should elevate methemoglobinemia on the differential list. In addition to this "saturation gap," signs and symptoms classically associated with methemoglobinemia include cyanosis refractory to oxygen therapy, decreased $\mathrm{SpO} 2$ often with a nadir of $85 \%$, chocolate-colored [12] or black/ brown blood $[6,8,9]$, physiologically appropriate $\mathrm{PaO} 2$ on $\mathrm{ABG}$, acidosis and tachycardia [12]. These are described in Table 2 [1].

\section{Management of Methemoglobinemia}

Current treatments for methemoglobinemia vary depending on the contributing factors whether genetic and/or drug exposure. For hereditary methemoglobinemia oxidant drugs should be avoided, but ascorbic acid may be of benefit if used daily [17].

For methemoglobinemia caused primarily by drug exposure, methylene blue infusion is used typically when methemoglobin levels are 30\% for asymptomatic and $20 \%$ for symptomatic patients. If the patient has underlying anemia, cardiac, or pulmonary comorbidities, lower thresholds of methemoglobin levels should be considered for administration of methylene blue. Interestingly, patients with hemoglobin $\mathrm{M}$ disease do not respond to ascorbic acid or methylene blue treatment, because individuals with this disease do not have symptoms. However, exchange transfusion may be used.

Because methylene blue depends on the availability of reduced NADPH, dextrose should be given in addition to methylene blue as it is used to form NADPH through the hexose monophosphate shunt [18]. Nicotinamide adenine dinucleotide (NADH) is also reduced from $\mathrm{NAD}+$ by catabolism of dextrose in glycolysis and therefore addition of dextrose helps replenish NADH. Alternative methods such as riboflavin are effective via flavin reductase in human erythrocytes and the reduction of methemoglobin. Ascorbic acid is a water-soluble
Table 2 Signs and symptoms associated with $\mathrm{MetHb}$ blood concentrations. Reprinted from [12]. Copyright (2014), with permission from Elsevier

\begin{tabular}{|c|c|c|}
\hline $\begin{array}{l}\text { Methemoglobin } \\
\text { concentration } \\
(\mathrm{g} / \mathrm{dL})\end{array}$ & $\begin{array}{l}\% \text { of total } \\
\text { hemoglobin }\end{array}$ & Symptoms \\
\hline$<1.5$ & $<10$ & None \\
\hline $1.5-3.0$ & $10-20$ & $\begin{array}{l}\text { Mild symptoms. } \\
\text { Cyanotic (blue/slate } \\
\text { gray) skin } \\
\text { discoloration, } \\
\text { chocolate brown } \\
\text { blood, no hypoxic } \\
\text { symptoms }\end{array}$ \\
\hline $3.0-4.5$ & $20-30$ & $\begin{array}{l}\text { Anxiety, light- } \\
\text { headedness, } \\
\text { headache, } \\
\text { tachycardia, } \\
\text { breathlessness, } \\
\text { syncopal attacks }\end{array}$ \\
\hline $4.5-7.5$ & $30-50$ & $\begin{array}{l}\text { Fatigue, confusion, } \\
\text { dizziness, tachypnea, } \\
\text { increased } \\
\text { tachycardia, } \\
\text { weakness }\end{array}$ \\
\hline $7.5-10.5$ & $50-70$ & $\begin{array}{l}\text { Coma, seizures, } \\
\text { arrhythmias, lactic } \\
\text { acidosis, CNS } \\
\text { depression, } \\
\text { dysrhythmias }\end{array}$ \\
\hline$>10.5$ & $>70$ & $\begin{array}{l}\text { Profound hypoxia, } \\
\text { death }\end{array}$ \\
\hline
\end{tabular}

reducing agent and a donor antioxidant. Cimetidine inhibits conversion of dapsone to its oxidizing metabolite, dapsone hydroxylamine, by the cytochrome P450 system, thereby preventing further development of dapsone-induced methemoglobinemia [2]. Ketoconazole has shown a similar mechanism of action in treatment of dapsone-related methemoglobinemia [19]. There is conflicting data regarding the efficacy of $\mathrm{N}$-acetyl cysteine 
and its ability as a reducing agent in methemoglobinemia. In vitro studies have demonstrated positive results, while a randomized control crossover study concluded that intravenous administration of $\mathrm{N}$-acetyl cysteine failed to enhance methemoglobin reduction $[1,3,12]$.

Treatment for symptomatic methemoglobinemia involves promoting the reduction of methemoglobin back to oxyhemoglobin through the use of methylene blue, ascorbic acid, riboflavin, and hyperbaric oxygen therapy. As a last resort in emergency situations where the previous therapies are insufficient, unavailable, or contraindicated, red blood cell transfusion therapy can be attempted in cases of critically elevated methemoglobin levels exceeding 70\% [11].

The detailed treatment for methemoglobinemia is intravenous administration of $1 \%$ methylene blue, in a dose of $1-2 \mathrm{mg} / \mathrm{kg}$ over a 5 -min interval, with repeat doses every $30 \mathrm{~min}$ to an hour if necessary. The total amount of methylene blue given should not exceed $7 \mathrm{mg} / \mathrm{kg}$ and any dose $15 \mathrm{mg} / \mathrm{kg}$ or greater will result in direct lysis of red blood cell. Rebound methemoglobinemia may occur up to $18 \mathrm{~h}$ after methylene blue administration, due to prolonged absorption of lipophilic agents (benzocaine) from adipose tissue. Serial measurements of methemoglobin levels should be performed following treatment with methylene blue [14]. Of note, methylene blue increases the reducing capacity of the $\mathrm{NADPH}-\mathrm{MHb}$ reductase system by acting as a cofactor in the electron transfer from NADPH to the oxidized methemoglobin [8]. Therefore, an adjuvant therapy to consider is ascorbic acid, which works by non-enzymatically reducing methemoglobin, although to a much lesser extent than methylene blue $[11,20]$. The substitution of ascorbic acid for methylene blue is necessary in circumstances where methylene blue is not available or is contraindicated. With regard to hemoglobin $\mathrm{M}$ disorder, methemoglobinemia does not respond to either ascorbic acid or methylene blue [4]. Methylene blue is also contraindicated in patients with G6PD deficiency. In these patients, the use of methylene blue can worsen methemoglobinemia and promote red blood cell lysis. This is because the reduction of methemoglobin by methylene blue is dependent on NADPH generated by G6PD [20]. Methylene blue can also act by reversibly inhibiting monoamine oxidase A (MOA), leading to a rise in serotonin levels. Therefore, methylene blue is also contraindicated in individuals on selective serotonin reuptake inhibitor therapy. Of note, there have been reported cases of methylene blue-induced acute encephalopathy and serotonin syndrome [21]. Therefore, the health care provider should be sure to take a detailed patient history, including any and all medications and/or supplements before making the decision to administer methylene blue.

There is no consistent recommendation regarding dosage of ascorbic acid for treatment of methemoglobinemia provided in the literature. The dosages and duration of treatment vary widely across these cases ranging from $1 \mathrm{~g}$ ascorbic acid as a one-time dose [reportedly lowering the patient's methemoglobin level from $26.2 \%$ to $2.1 \%$ within $6 \mathrm{~h}$ of dosing] [22] to high-dose $10 \mathrm{~g}$ ascorbic acid every $6 \mathrm{~h}$ [22]. Dosing recommendations from four case reports of successful resolution of methemoglobinemia using only vitamin $\mathrm{C}$ have been outlined in a 2016 review by Sahu et al. [23]. See Fig. 3, used with permission from [24].

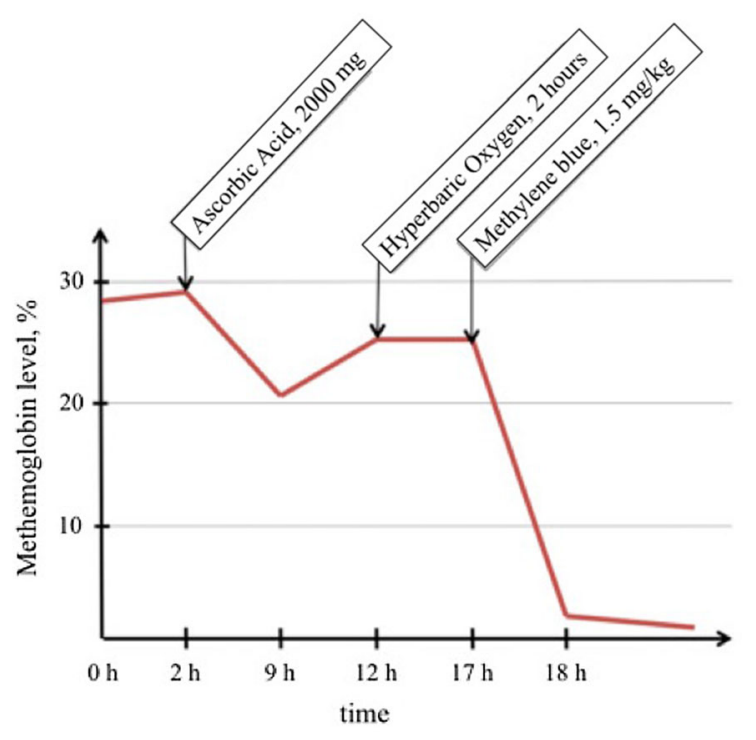

Fig. 3 Chronologic observation of patient's methemoglobin levels and its relation to treatments. Reproduced from [24] 


\section{CONCLUSIONS}

Methemoglobinemia can present as a challenge for clinicians in both diagnosis and treatment. Clinically, methemoglobinemia may manifest as dyspnea, nausea, cyanosis, and tachycardia to much more extreme symptoms such as lethargy, stupor, and deteriorating consciousness. Methemoglobinemia can be diagnosed by a discrepancy between the $\mathrm{SpO} 2$ and $\mathrm{SaO} 2$ that is refractory to oxygen therapy, signs of cyanosis, decreased $\mathrm{SpO} 2$ hovering at $85 \%$, chocolate-colored blood, acidosis, and tachycardia, and most effectively with use of CO-oximetry. The most common drugs that cause methemoglobinemia such as benzocaine and lidocaine, antibiotics including dapsone, and gases including nitric oxide are summarized in Table 3. A variety of inherited forms of methemoglobinemia exist including congenital methemoglobinemia, hemoglobin $\mathrm{M}$ disease, G6PD deficiency, and autosomal recessive deficiency of cytochrome b5 reductase in which oxidant drugs should be avoided and exchange transfusion may be beneficial. Treatment of methemoglobinemia includes methylene blue, ascorbic acid, riboflavin, hyperbaric oxygen therapy, and even RBC transfusion for refractory or severe cases. Methylene blue is used for cases primarily caused secondary to drug exposure. Methylene blue is given in these cases for greater than 30\% in asymptomatic patients and greater than $20 \%$ in symptomatic patients; however, lower thresholds should be considered for infants, premature infants, the elderly, and patients with underlying anemia, cardiac, or pulmonary comorbidities.

\section{LIMITATIONS}

Only clinically relevant information was gathered, analyzed, and presented in this paper. We were unable to recommend experimental therapies such as intralipid infusion, ketoconazole, cimetidine, or even hyperbaric oxygen because of lack of further research. The Evelyn-Malloy assay can be used to increase specificity, but there is a lack of evidence on quantifying the increase itself or mention of its effects on sensitivity. There is a lack of data on the use of daily ascorbic acid as a preventative measure within populations mentioned prior to being at an increased risk. There are multiple studies on animal models on adjunct therapy with methylene blue but no mention of synergistic effects. On the basis of the low side effect profile of both ascorbic acid and riboflavin and enough data published on their possible effects, we recommend their use prior to methylene blue when enzyme testing is underway in emergent settings or methylene blue is unavailable. No consistent recommendations exist regarding effective dosages of ascorbic acid or riboflavin for treatment of methemoglobinemia and vary from study to study. Further studies with larger sample sizes of treatment strategies for different conditions with methemoglobinemia are recommended.

\section{FINAL RECOMMENDATIONS}

With the over the counter availability of topical anesthetics and frequent use in the emergency room for airways management, intubation in

Table 3 Incidence of most drugs that cause methemoglobinemia. Modified from [15]

\begin{tabular}{llll}
\hline Class of drugs & Common & Uncommon & Rarely \\
\hline Analgesics & Phenazopyridine, phenacetin & & Acetaminophen, fentanyl \\
Anticonvulsants & & & Phenobartbital \\
Anti-infectious agents & Dapsone, primaquine & Sulfonamides & Nitrofurantoin, chloroquine \\
Local/topic anaesthetics & Benzocaine, prilocaine & Tetracaine, cetacaine, amethocaine & Lidocaine \\
Vasodilators & Nitrite derivatives & Nitrate derivatives & \\
Miscellaneous & & Methylene blue, metoclopramide & \\
\hline
\end{tabular}


the operating room, and endoscopic procedures there have been a significant number of cases of methemoglobinemia reported in the past decade. A high suspicion for methemoglobin should follow any presentation of hypoxic and cyanotic patients who are not improving with 100\% FiO2 oxygen therapy. Taking a thorough history and investigating recent medication exposure while giving great importance to a discrepancy between the $\mathrm{SpO} 2$ and the $\mathrm{SaO} 2$ recorded on an $\mathrm{ABG}$ that is refractory to oxygen therapy is recommended. The most clinically effective measurement method is through use of a CO-oximeter, which directly measures the light wavelength absorption of methemoglobin in the blood. Methylene blue infusion is recommended when methemoglobin levels are $30 \%$ for asymptomatic and $20 \%$ for symptomatic patients [11].

\section{ACKNOWLEDGEMENTS}

Funding. No funding or sponsorship was received for this study or publication of this article.

Authorship. All named authors meet the International Committee of Medical Journal Editors (ICMJE) criteria for authorship for this article, take responsibility for the integrity of the work as a whole, and have given their approval for this version to be published.

Disclosures. John N. Cefalu, Tejas V. Joshi, Matthew J. Spalitta, Carson J. Kadi, James H. Diaz, Jonathan P. Eskander and Elyse M. Cornett have nothing to disclose. Alan D. Kaye is a member of the journal's Editorial Board.

Compliance with Ethics Guidelines. This article is based on previously conducted studies and does not contain any studies with human participants or animals performed by any of the authors.

Data Availability. Data sharing is not applicable to this article as no datasets were generated or analyzed during the current study.
Open Access. This article is licensed under a Creative Commons Attribution-NonCommercial 4.0 International License, which permits any non-commercial use, sharing, adaptation, distribution and reproduction in any medium or format, as long as you give appropriate credit to the original author(s) and the source, provide a link to the Creative Commons licence, and indicate if changes were made. The images or other third party material in this article are included in the article's Creative Commons licence, unless indicated otherwise in a credit line to the material. If material is not included in the article's Creative Commons licence and your intended use is not permitted by statutory regulation or exceeds the permitted use, you will need to obtain permission directly from the copyright holder.To view a copy of this licence, visit http://creativecommons.org/licenses/by$\mathrm{nc} / 4.0 /$.

\section{REFERENCES}

1. David, Sawal NS, Hamzah MNS Bin, Rajabalaya R. The blood blues: a review on methemoglobinemia. J Pharmacol Pharmacother. 2018;9(1):1. http:// www.jpharmacol.com/article. asp?issn=0976-500X; year $=2018$; volume $=9 ;$ issue $=1$; spage $=1$; epage $=5$; aula st=David. Cited 10 Jun 2019.

2. Coleman M, Rhodes L, Scott A, et al. The use of cimetidine to reduce dapsone-dependent methaemoglobinaemia in dermatitis herpetiformis patients. Br J Clin Pharmacol. 1992;34(3):244-9. http://www.ncbi.nlm.nih.gov/pubmed/1389948. Cited 4 Jun 2019.

3. Steinberg MH. Disorders of hemoglobin : genetics, pathophysiology, and clinical management. Cambridge: Cambridge University Press; 2001. p. 1268.

4. Rehman HU. Methemoglobinemia. West J Med. 2001;175(3):193-6. http://www.pubmedcentral. nih.gov/tocrender.fcgi?journal=183\&action=archive. Cited 5 Jun 2019.

5. Rodak BF, Fritsma GA, Keohane EM. Hematology: clinical principles and applications. Philadelphia: Elsevier Saunders; 2012. p. 864.

6. Cho SS, Park YD, Noh JH, Kang KO, Jun HJ, Yoon JS. Anesthetic experience of methemoglobinemia detected during general anesthesia for gastrectomy of advanced gastric cancer-a case report. Korean J 
Anesthesiol. 2010;59(5):340-3. http://www.ncbi. nlm.nih.gov/pubmed/21179297. Cited 5 Jun 2019.

7. Trapp L, Will J. Acquired methemoglobinemia revisited. Dent Clin N Am. 2010;54(4):665-75. http://www.ncbi.nlm.nih.gov/pubmed/20831930. Cited 5 Jun 2019.

8. Young B. Intraoperative detection of methemoglobinemia in a patient given benzocaine spray to relieve discomfort from a nasogastric tube: a case report. AANA J. 2008;76(2):99-102. http://www. ncbi.nlm.nih.gov/pubmed/18478813. Cited 5 Jun 2019.

9. Kuş A, Berk D, Hoşten T, Gürkan Y, Solak M, Toker $\mathrm{K}$. The role of preoperative evaluation for congenital methemoglobinemia. Turkish J Anaesthesiol Reanim. 2014;42(4):223-6. http://www.ncbi.nlm. nih.gov/pubmed/27366424. Cited 5 Jun 2019.

10. Cohen RJ, Sachs JR, Wicker DJ, Conrad ME. Methemoglobinemia provoked by malarial chemoprophylaxis in Vietnam. $\mathrm{N}$ Engl J Med. 1968;279(21):1127-31. http://www.nejm.org/doi/ abs/10.1056/NEJM196811212792102. Cited 4 Jun 2019.

11. do Nascimento TS, Pereira ROL, de Mello HLD, Costa J. Methemoglobinemia: from diagnosis to treatment. Rev Bras Anestesiol. 2008;58(6):651-64. http://www.ncbi.nlm.nih.gov/pubmed/19082413. Cited 5 Jun 2019.

12. Cortazzo JA, Lichtman AD. Methemoglobinemia: a review and recommendations for management. J Cardiothorac Vasc Anesth. 2014;28(4):1043-7. http://www.ncbi.nlm.nih.gov/pubmed/23953868. Cited 5 Jun 2019.

13. Panin G, Pernechele M, Giurioli R, et al. Cytochrome b5 reductase activity in erythrocytes and leukocytes as related to sex and age. Clin Chem. 1984;30(5):701-3. http://www.ncbi.nlm.nih.gov/ pubmed/6713629. Cited 4 Jun 2019.

14. OpenAnesthesia. Methemoglobinemia: diagnosis. https://www.openanesthesia.org/ methemoglobinemia_diagnosis/. Cited 4 Jun 2019.

15. Alanazi MQ, Menyfah D, Alanazi Q. Drugs may be induced methemoglobinemia. 2017. https://www. longdom.org/open-access/drugs-may-be-inducedmethemoglobinemia-2329-8790-1000270.pdf. Cited 12 Jun 2019.
16. And KAE, Malloy HT. Microdetermination of oxyhemoglobin, methemoglobin, and stjlfhemoglobin in a single sample of blood. http://www.jbc.org/. Cited 4 Jun 2019.

17. Bolyai JZ, Smith RP, Gray CT. Ascorbic acid and chemically induced methemoglobinemias. Toxicol Appl Pharmacol. 1972;21:176-85. https://www. cabdirect.org/cabdirect/abstract/19721408236.

Cited 4 Jun 2019.

18. Roigas H, Zoellner E, Jacobasch G, Schultze M, Rapoport S. Regulatory factors in methylene blue catalysis in erythrocytes. Eur J Biochem. 1970;12(1): 24-30. http://www.ncbi.nlm.nih.gov/pubmed/ 4392179. Cited 4 Jun 2019.

19. Tingle MD, Coleman MD, Park BK. An investigation of the role of metabolism in dapsone-induced methaemoglobinaemia using a two compartment in vitro test system. $\mathrm{Br} \mathrm{J}$ Clin Pharmacol. 1990;30(6):829-38. http://www.ncbi.nlm.nih.gov/ pubmed/2288829. Cited 4 Jun 2019.

20. Yildirim B, Karagoz U, Acar E, et al. A case report of prilocaine-induced methemoglobinemia after liposuction procedure. Case Rep Emerg Med. 2015;2015:282347. http://www.ncbi.nlm.nih.gov/ pubmed/26199764. Cited 5 Jun 2019.

21. Shopes E, Gerard W, Baughman J. Methylene blue encephalopathy: a case report and review of published cases. AANA J. 2013;81(3):215-21. http:// www.ncbi.nlm.nih.gov/pubmed/23923673. Cited 4 Jun 2019.

22. Park EJ, Lee M, Min Y-G. Successful treatment of NO-induced methemoglobinemia with low-dose vitamin C. Clin Toxicol. 2017;55(7):686-686. http://www.ncbi.nlm.nih.gov/pubmed/28438052. Cited 4 Jun 2019.

23. Sahu KK, Dhibar DP, Gautam A, Kumar Y, Varma SC. Role of ascorbic acid in the treatment of methemoglobinemia. Turkish J Emerg Med. 2016;16(3):119-20. http://www.ncbi.nlm.nih.gov/ pubmed/27857990. Cited 5 Jun 2019.

24. Toker I, Yesilaras M, Tur FC, Toktas R. Methemoglobinemia caused by dapsone overdose: which treatment is best? Turkish J Emerg Med. 2015;15(4): 182-4. http://www.ncbi.nlm.nih.gov/pubmed/ 27239625. Cited 4 Jun 2019. 